\title{
Comparative study of diagnostic methods for determining the incidence of malaria parasite among children attending the State Specialist Hospital Ikare-Akoko, Ondo State, Nigeria
}

\author{
*Olajubu Abiose Festus, Ojo Olubunmi Esther \\ Department of Microbiology, Adekunle Ajasin University, Akungba-Akoko, Ondo \\ State, Nigeria. *Email: festus.olajubu@aaua.edu.ng \\ DOI: $10.31964 / \mathrm{mltj} . v \%$ vi\%i.195
}

\begin{abstract}
Malaria is an endemic disease in Sub-Saharan Africa, and it accounts for the death of more than 1 million children annually. The objective of this study was to determine the incidence of malaria parasite among children between 2-15 years of age visiting State Specialist Hospital Ikare-Akoko, Ondo State, Nigeria, using Rapid diagnostic test kits and staining methods. The study was conducted between July and December 2017. Two millimeters of venous blood samples were collected from each of the 300 enlisted children and stored in an anticoagulated specimen bottle. Thick and thin blood films were prepared from the collected samples, stained and examined for the presence of malaria parasite using the Microscope. Three Rapid diagnostic test kits were also used. Two hundred and thirty-six (78.68\%) of the 300 children investigated were found to have malaria parasite infection. Gender distribution showed that more male $(45.67 \%)$ were infected than females $(33.01 \%)$. Infections due to age distribution revealed that children within the ages of 2-5 years were more infected (39.3\%) than children in other age range (6-10 years, $23.34 \%$ and 11-15 years, $17 \%$ ). There was no statistical difference in the results obtained from the various techniques used $(p<0.05)$ even though Carestart kit appeared less sensitive. Plasmodium falciparum was found to be the cause of malaria infection in Ikare-Akoko. Since there was no statistical difference in the two methods examined, the use of rapid diagnostic kits should be encouraged while more awareness campaign and efforts geared towards the prompt and adequate treatment of infected individuals.
\end{abstract}

Keywords: Plasmodium falciparum; incidence; Ikare-Akoko; children; rapid test kits

\section{INTRODUCTION}

Malaria is one of the most common protozoan parasite infections of public health importance. It causes economic loss and premature death in Tropical and Subtropical countries (Cheesbrough, 2003). Though preventable, its spread has reached an epidemic proportion in many countries. African children under five years and pregnant women are most at risk of malaria (WHO, 2000).

Nigeria bears up to $25 \%$ of the malaria disease burden in Africa, hence contributing significantly to the millions of life lost per year in the region, which mostly consist of children and pregnant women (NSS, 2005). Malaria in Nigeria is endemic and constitutes a significant public health problem. Despite the temporary nature of the disease; malaria accounts for up to $11 \%$ of maternal mortality, $25 \%$ of infant mortality, and $30 \%$ of under-five mortality, resulting in about 300,000 childhood death annually. The vast majority of deaths occur among children below five years of age 
and pregnant women (WHO, 2015), especially in a remote rural areas with poor access to health care centers. Fatally afflicted children often die less than 72 hours after developing symptoms. In those children who survive, malaria drains vital nutrients from them impairing their physical and intellectual development (Fawole and Onadeko, 2001). It estimated that more than one million children living in Africa die annually from direct and indirect effects of malaria infection (WHO, 2000).

Despite the combined efforts by 102 countries to eradicate malaria, it remains the primary disease in the world today in terms of morbidity/mortality and economic burden (Mockenhaupt et al., 2004). Falciparum malaria is the most dangerous form of the disease resulting in life-threatening complication such as anaemia and cerebral malaria (Kere et al., 1993). The pattern of exposure to malaria infection, the types of treatment and the degree of compliance with the anti-malaria regimen, local drug resistance patterns, and an individual's age and genetic makeup all tend to influence the severity of the disease (Mannoor et al., 2001). The parasite attacks and destroy the red blood cell and may affect vital body organs like brain, and liver. Malaria is transmitted to people through the bites of infected female Anopheles mosquitoes. The main species that commonly cause malaria in human include Plasmodium ovale, $P$. falciparum, $P$. malariae, and $P$. ovale (Ukoli, 1990). Each species of the malaria parasite has specific identification features under the microscope. The symptoms they produce could be as varied as the species themselves. Two or more species can live in the same area and infect a single person at the same time. Plasmodium falciparum is responsible for most malaria deaths, especially in Africa. The infection can develop suddenly and produce severe life-threatening complications. With prompt, effective treatment, however, it is almost always curable (WHO, 1995).

Wrong diagnosis can further aggravate the complication of malaria infection. Malaria rapid diagnostic kits are freely used in Nigeria even by retail, pharmaceutical outlets. As good as this may appear, the sensitivity and efficacy of the packages need regular surveillance by comparing them with the microscopic method, which directly demonstrates the presence of the parasite in situ. Three primary malaria rapid diagnostic kits are being used in Nigeria, which is Onsite, SD Bioline, and Carestart. If the efficacy of the package compares favourably well with a microscopic method, then their use can be widely advocated as more case detection will be achieved, and prompt treatment can be administered. This might curb further spread and reduction in mortality due to malaria infection. This study was therefore designed to determine the incidence of malaria parasite among children between 2-15 years of age visiting State Specialist Hospital lkare-Akoko, Ondo State, Nigeria and compare the use of Rapid Diagnostic test Kits commonly available with the golden microscopic methods.

\section{MATERIALS AND METHODS \\ Study Design and Area.}

This study was carried out at the State Specialist Hospital Laboratory, IkareAkoko. Akoko North East Local Government Area of Ondo State.

Ikare-Akoko is a city in Southwestern Nigeria, and it is about $100 \mathrm{~km}$ from Akure, the Ondo State capital. The town is the divisional headquarters of the old Akoko Division. Based on the Local Government System now practiced in Nigeria, the city is currently the Headquarter of Akoko North-East Local Government. The town lies in the Lat. $7^{\circ} 31^{\prime} 0^{\prime \prime} \mathrm{N}$, Long $5^{\circ} 45^{\prime} 0^{\prime \prime} \mathrm{E}$. The mean annual rainfall is about $1300 \mathrm{~mm}$ 
and mean temperature of $20^{\circ} \mathrm{C}$. The vegetation characterized by wooden shrubs, palms, moist deciduous trees, and herbaceous plant. It is usually with dense vegetation in the rainy season and sparse in the dry season. State Specialist Hospital, Ikare-Akoko is a secondary healthcare facility serving many smaller towns and villages in Akoko.

\section{Sample Size}

The study was conducted among three hundred (300) children, within the age range of 2-15 years who attended State Specialist Hospital, Ikare-Akoko, Nigeria, between July and December 2017.

\section{Sample Collection and Procedure.}

Blood samples were aseptically collected from the veins of the respondents using a sterile needle and syringes. Before blood collection, the forearms were cleaned with cotton wool dampened with $70 \%$ ethanol to remove dirt and oils. With the use of tourniquet, the inflamed veins were gently pierced with sterile needles and two millilitres of blood drawn. (Cheesbrough, 2000; Mukherjee, 2006). Thick and thin blood films were made on clean slides and labelled accordingly as recommended by the World Health Organisation (WHO, 2000). The slides were stained with Giemsa and Leishman stains respectively and examined under the Microscope. Rapid diagnostic test kits; Onsite Malaria Pf/Pv Ab Combo Rapid Test (CTK Biotech, San Diego CA 92121, USA). CarestartTM \{malaria HRP2 (PF)\} manufactured by Access Bio, Inc, Somerset NJO8873, USA and SD Bioline were used to examine blood samples for the presence of Plasmodium parasites or its antibodies following the manufacturer's guidelines. The kits work on different principles. Before the commencement of the study, approval was sought and granted by the Management of the Hospital.

\section{RESULTS AND DISCUSSION}

Table 1 shows the distribution of malaria in relation to age and sex. In ages 25, 85 males and 69 females were tested for which 68 and 50 were infected respectively. These represents $22.67 \%$ and $16.67 \%$ respectively. While in ages $6-10$, 50 males and 33 females were examined out of which 38 were positive for males and 29 for females representing $12.67 \%$ and $9.67 \%$ respectively. In the same vein, within the ages of 11-15, 40 males and 26 females were tested out of which 31 and 20 were positive respectively, representing $10.33 \%$ and $6.67 \%$. In all, a total of 172 males and 128 females were examined. Among these, 137 (45.67\%) male infected, and 99 (33.01\%) among females. Prevalence of malaria parasite in Ikare-Akoko community of Ondo State, Nigeria indicated that out of 300 children examined 236 $(78.0 \%)$ of them were infected with the malaria parasite. The children within the ages of $2-5$ years were more infected (39\%) than the children from other age range, this was followed by those between $6-10$ years $(22.34 \%)$ and the least was $11-15$ years $(17 \%)$. 
Table 1: Distribution of malaria in relation to age and sex

\begin{tabular}{ccccccc}
\hline \multirow{2}{*}{$\begin{array}{c}\text { Age } \\
\text { (Years) }\end{array}$} & \multicolumn{2}{c}{$\begin{array}{c}\text { Number } \\
\text { Examined }\end{array}$} & \multicolumn{2}{c}{$\begin{array}{c}\text { Number } \\
\text { Infected }\end{array}$} & \multicolumn{2}{c}{ Prevalence\% } \\
& Male & Female & Male & Female & Male & Female \\
\hline $2-5$ & 82 & 69 & 68 & 50 & $22.67 \%$ & $16.67 \%$ \\
$6-10$ & 50 & 33 & 38 & 29 & $12.67 \%$ & $9.67 \%$ \\
$11-15$ & 40 & 26 & 31 & 20 & $10.33 \%$ & $6.67 \%$ \\
Total & 172 & 128 & 137 & 99 & $45.67 \%$ & $33.01 \%$ \\
\hline
\end{tabular}

Tables 2 and 3 show the overall distribution of Plasmodium parasites by sex and ages which were calculated by chi-square test, concluded that there were significant differences between infection by sex and age since $X^{2}$ estimated value in male (16.92) and female (14.36) is greater than $X^{2}$ tabulated (5.99) value at $p<0.05$ and degree of freedom 2 respectively, as shown below:

Table 2: Chi-square finding for infected male

\begin{tabular}{ccccc}
\hline $\begin{array}{c}\text { Age } \\
\text { (Year) }\end{array}$ & Observed $(\mathrm{O})$ & Expected $(\mathrm{E})$ & $(\mathrm{O}-\mathrm{E})$ & $(\mathrm{O}-\mathrm{E})^{2}$ \\
\hline $2-5$ & 68 & 45.67 & 22.33 & 498.63 \\
$6-10$ & 38 & 45.67 & -7.67 & 58.83 \\
$11-15$ & 31 & 45.67 & $-14,67$ & 215.21 \\
& 137 & & & 772.67 \\
\hline
\end{tabular}

$X^{2}=\frac{\Sigma(O-E)^{2}}{E} \quad=\frac{772.67}{45.67}=16.92$

Degree of freedom $d_{f}=n-1(n=3)$

$X^{2}$ tabulated @ $0.05=5.99$

$$
3-1=2
$$

Table 3: Chi-square finding for infected female

\begin{tabular}{ccccc}
\hline Category & Observed $(\mathrm{O})$ & Expected $(\mathrm{E})$ & $(\mathrm{O}-\mathrm{E})$ & $(\mathrm{O}-\mathrm{E})^{2}$ \\
\hline $2-5$ & 50 & 33.00 & 17 & 289 \\
$6-10$ & 29 & 33.00 & -4 & 16 \\
$11-15$ & 20 & 33.00 & -13 & 169 \\
& 99 & & & 474 \\
\hline
\end{tabular}

$X^{2}=\frac{\Sigma(O-E)^{2}}{E} \quad=\frac{474=14.36}{33.00}$

Degree of freedom $d_{f}=n-1(n=3)$

$X^{2}$ tabulated @ $0.05=5.99$

$\mathrm{X}^{2}=$ Chi square

$\Sigma=$ Summation

$\mathrm{O}=$ Observed frequency

$\mathrm{E}=$ Expected frequency 
Table 4: Comparison between the diagnostic methods used.

\begin{tabular}{lccccccc}
\hline Method Used & $+\mathrm{ve}$ & -ve & $\begin{array}{l}\text { Total } \\
\text { Mrue }\end{array}$ & $\begin{array}{l}\text { False } \\
+\mathrm{ve}\end{array}$ & $\begin{array}{l}\text { True } \\
\text { +ve }\end{array}$ & $\begin{array}{l}\text { False } \\
\text {-ve }\end{array}$ \\
\hline Microscopy(Thick film) & 75 & 25 & 100 & 75 & 0 & 24 & 1 \\
Onsite Combo (RDT) & 80 & 20 & 100 & 76 & 4 & 16 & 4 \\
Carestart (RDT) & 43 & 57 & 100 & 42 & 1 & 24 & 33 \\
SD Bioline (RDT) & 78 & 22 & 100 & 72 & 6 & 19 & 3 \\
\hline
\end{tabular}

RDT = Rapid Diagnostic Test

Malaria is one of the significant reasons for visitations to Hospitals in the study area. This situation results in economic loss, which often comes from the cost of diagnosis and treatment and absenteeism from work.

In this study, the prevalence of falciparum malaria in children between $2-15$ years is $78.67 \%$. It is observed that children between the ages of $2-5 y e a r s$ had the highest (39.34\%) prevalence of Plasmodium infection compared with the other age groups. This situation may be because, at that age, their immunity to parasitic infections has not been fully developed. Although it has been established that residual resistance derived from mothers could be very useful in younger children, environmental conditions and the inability of children of this age in the study area to ward-off environmentally induced mosquito attacks predisposed them to malaria attack. This finding correlates with the observations made by WHO (2000); that the malaria burden is more substantial in Sub-Saharan Africa than other parts of the world where an estimated $90 \%$ of all deaths due to malaria occur, and children under $5 y e a r s$, account for $78 \%$ of all deaths.

The prevalence of Plasmodium infection has been found to reduce with other ages $6-10$ and 11 - 15years $(22.34 \%$ and $17 \%)$ respectively, this could be attributed to the fact that children of this age have developed immunity against Plasmodium parasite. It appears that as they grow older, they become more careful with precautionary measures against the transmission of malaria parasite infections and are more likely to adhere to instructions of sleeping under an insecticide-treated net (ITN).

The present study has shown that Plasmodium infections were more common in the male than in the female subjects. However, studies have shown that females have better immunity to parasitic diseases and this was attributed to some genetic and hormonal factors (Krongstad, 1996)

Prevalence of malaria found in this study was higher than what had been reported by some authors. For instance, Umaru and Uyaibasi in 2015 reported prevalence of $35.7 \%$ in children attending General Hospital Markafi, Kaduna State. Ani, (2015), published prevalence of $37.5 \%$ in Isu Community in Ebonyi state. Sunday and Imaode (2017), reported a prevalence of 38.58 for children attending Medical Centre, Yenagoa, Bayelsa State. But similar to the values previously reported by some authors. Nmadu, et al. (2015) reported a prevalence of $64 \%$ in 2 15 years old children visiting Gwarinpa General Hospital Life Camp, Abuja. Abah and Temple (2015) reported the incidence of malaria parasite among asymptomatic Primary School Children in Angiama Community, Southern ljaw Local Government Area, Bayelsa State as $63.3 \%$. Okeke et al. (2016) reported an overall prevalence of malaria in a Community survey in Anambra State as $46.30 \%$. The observed difference could be due to variations in the target population, as only symptomatic volunteers were enlisted in this study. 
The prevalence of species of malaria parasite shows that Plasmodium falciparum was responsible for all the infections observed. This agrees with an earlier observation by WHO (2015), that majority of malaria disease in Africa are caused by Plasmodium falciparum, the most dangerous of the four human malaria parasites, others being Plasmodium vivax, Plasmodium malariae and Plasmodium ovale. Plasmodium falciparum infection is the primary cause of morbidity and mortality, especially in aged less than 5years (WHO, 2015).

The high prevalence rate, in this study area, could result to childhood anemia and other severe condition such as cerebral malaria as reported by other workers (Bolvin, 2002; Sotimehin et al., 2008). Majority of households do not prevent mosquito bites and disease transmission in any way. There is, therefore, the need to intensify awareness and education of parents, and it is also essential to avoid stagnant pools and poor environmental conditions, which encourage the breeding of mosquitoes.

\section{Comparison and Efficacy of the diagnostic test methods.}

Parasite-based routine malaria diagnosis is focused on detection of asexual parasite stage in the stained blood smears using microscopy or detection of parasite antigen using Rapid Diagnostic Test kits (RDTs). One hundred (100) patients were screened randomly to compare the efficacy of all the diagnostic method used, the rapid diagnostic test (RDTs) kits detected malaria in some patients, who were tested negative by microscopy, these were denoted as false positive. False positive has been reported in other investigations, but they appear to play a minor role in the usefulness of malaria test for clinical settings. False positive reactions may occur in individuals who have been recently treated for malaria, other causes of false-positive results are persistent of viable asexual stage parasitemia, below the detection limit of microscopy and persistence of antigens due to sequestration. This sequestration of malaria parasite at the time of blood collection is an entirely unknown factor. There are few cases of clinical evidence of parasitemia, the RDT kit also tests positive whereas microscopy could not detect the parasite which is at the early stage of development. This finding added weight to the usefulness of the RDTs, its advantages over microscope when the parasites sequestered in the cerebral and placental malaria. The study results revealed that microscopy, Onsite Malaria Pf/Pv $\mathrm{Ab}$ Combo and SD Bioline (RDT) showed an appreciable effectiveness. These three diagnostic methods mentioned above showed a higher ability to detect $P$. falciparum and has a higher sensitivity when compared with CarestartTM malaria HRP2 diagnostic kit which has a lower sensitivity in detecting malaria parasite in whole blood.

It has been suggested that insecticide-treated nets (ITNs) may also curb the spread of antimalarial drug resistance (Olasehinde et al., 2010). It is also essential to avoid stagnant pools and poor environmental conditions which encourage the breeding of mosquito (Lucas and Giles, 1998; FMOH, 2001) as measures to curb its spread.

\section{CONCLUSION}

This study has established that the prevalence $(78.7 \%)$ of the malaria parasite in Ikare-Akoko community of Ondo State is high. Though this might be considered normal since only symptomatic patients were enlisted in the study. However, coordinated efforts to reduce malaria death to near zero in the area is advocated. 
Since there was no statistical difference between the use of rapid diagnostic test kits and microscopic method, the use of RDT can be encouraged especially in remote villages with no access to any other form of diagnostic process.

\section{ACKNOWLEDGMENT}

The authors are grateful to Scientist (Mrs) Akinbulumo and Dr (Mrs) Ogunmodede and all other staff of the State Specialist Hospital Ikare-Akoko for their support.

\section{REFERENCES}

Abah, A.E and Temple B (2015). Prevalence of Malaria Parasite among Asymptomatic Primary School Children in Angiama Community, Bayelsa State, Nigeria. Tropical Medicine and Surgery 4, 203.

Ani, O.C. (2015). Malaria Parasitaemia Among Residents of Isu Community, Onicha Local Government Area of Ebonyi State. International journal of Scientific Research 4(11), 263-266.

Boivin, M.J. (2002). Effects of early cerebral malaria on cognitive ability in Senegalese children. Journal Development and Behavioral Pediatrics 23(5), 353-64

Cheesbrough, M. (2003). District Laboratory Practice in Tropical Countries. PCV and red cell indicies. Cambridge University Press Edinburgh, United Kingdom. Fifth Edition. Pp 310 -313.

Fawole, O.I. and Onadeko, M.O. (2001). Knowledge and Management of Malaria in Under Five Children by Primary Health Care Workers in Ibadan South East Local Government Area. Nigeria. Post Graduate Medical Journal, 8(I), I-5.

Federal Ministry of Health (2001). National Malaria and Vector Control Division. Federal Ministry of Health Abuja Nigeria.I-8.

Kere, N.K., Keni, J.F., Bobogara, A., Webber, R.H. and Southgate, B.A. (1993). The economic impact of Plasmodium falciparum malaria on education investment: A Pacific island case study. Southern Asian J Tropi Med. Public Health, (24), $659-663$.

Krongstad, D.J. (1996). Malaria as a re-emerging disease Epidemiology. Rev. 18:7789

Lucas, A.O. and Gilles, H.M. (1998). A New Short Textbook of Preventive Medicine for the Tropics. Malaria, Great Britain ELBS with Edward A11101d. Publishers: 188 - 192.

Mannoor, M.K., Weerasinghe, A., Halder, R.C., Reza. S., Morshed, M., Ariyasinghe, A., Watanabe, H., Sekikawa, H. and Abo, T. (2001). Resistance to malarial infection is achieved by the cooperation of NK I.I (+) and NK $1.1(-)$ subsets of intermediate TCR cells which are constituents of innate immunity. Cell Immunology, 211(2), 96-1 04.

Mockenhaupt, F., Ehrhardt, S., Burkhardt, J., Bosomtwe, S., Laryea, S., Anemana, S., Otchwemnah, R., Cramer, J., Dietz, E., Gellert, S. and Bienzle, U. (2004). Manifestation and outcome of severe malaria in children in northern Chana. Am J Trop Med Hyg, 71(2), 7-72.

Mukherjee, K.L. (2006). Medical Laboratory Technology: A Practical Manual for Routine Diagnostic Test. Tata McGraw-Hill Publishing Company Limited, New Delhi, India. PP 456 
National Surveillance Systems (2005). Epidemiological Data, Roll Back Malaria Monitoring and Evaluation. Nigeria W.H.O Publications. PP24

Nmadu, P.M., Peter, E., Alexander, P., Koggie, A.Z. and Maikenzi, J.I. (2015) The Prevalence of Malaria in Children between the Ages 2-15 Visiting Gwarinpa General Hospital Life-Camp, Abuja, Nigeria. Journal of Health Science, 5(3), 47-51.

Okeke, O.P., Imakwu, C.A., Eyo, J.E. and Okafor, F.C. (2016). Prevalence of malaria infection in children in Anambra state, Nigeria after change of policy from presumptive/clinical to confirmed diagnosis. Animal Research International, 13(1), 2385 - 2391.

Olasehinde, G.I., Ajayi, A.A., Taiwo, S.O., Adekeye, B.T. and Adeyeba, O.A. (2010). Prevalence and Management of falciparum Malaria among infants and children in Ota, Ogun State, South western Nigeria. African journal of clinical and experimental microbiology, (2), 45-47

Sotimehin, S.A., Runsewe-Abiodun, T.A., Oladapo, O.T., Njokanma, O.F. and Olanrewaju, D.M. (2008). Possible Risk Factors for Congenital Malaria at a Tertiary Care Hospital in Sagamu, Ogun State, Southwest Nigeria. Journal of Tropical Pediatrics, (1), 55

Sunday, E.B. and Imaode, L.N. (2017). Prevalence of malaria parasitemia among children between 1-10 years old attending Federal Medical Centre, yenagoa, Bayelsa state, Nigeria. Ec pharmacology and Toxicology 3(2):43-48.

Ukoli, S.A. (1990). Introduction to Parasitology in Tropical Africa. Distinquishing features of the four species of malaria infecting man. John Wiley \& Sons Text flow Ltd Ibadan, Nigeria. Pp 399 - 408.

Umaru, M.L. and Uyaiabasi, G.N. (2015). Prevalence of Malaria in Patients Attending the General Hospital Makarfi, Kaduna - State, North-Western Nigeria. American journal of infectious Diseases and Microbiology, 3(1), 1-5.

W.H.O. (1995). Methods of counting malaria parasites in thick blood films. Bench aids for the diagnosis of malaria. Geneva, World Health Organisation. Pp.1-8.

W.H.O. (2000) Press Release WHO/48 Fact Sheet. Geneva W.H.O publications: 118.

W.H.O. (2015). Malaria Fact sheet No 94. World Health Organization Geneva 27, Switzerland. 